\title{
Superficial Injury of Cornea
}

National Cancer Institute

\section{Source}

National Cancer Institute. Superficial Injury of Cornea. NCI Thesaurus. Code C35048.

Trauma to the corneal epithelium. 